\title{
The Advantages of Jointly Considering First and Second Language Vocabulary Skills Among Emergent Bilingual Children
}

May-Britt Monsrud ${ }^{1}$, Veslem $\varnothing y$ Rydland ${ }^{2}$, Esther Geva ${ }^{3}$, Anne-Cathrine Thurmann-Moe ${ }^{4}$ and Solveig Halaas Lyster ${ }^{5}$

Keywords: conceptual score, assessment, language proficiency, receptive and expressive vocabularies

A large body of research demonstrates that many bilingual students struggle with gaining command of vocabulary at the same level as that of their monolingual peers in school language (e.g, Farnia \& Geva, 2011). It is a well-established observation that insufficient vocabulary skills constitute a bottleneck for reading comprehension and ultimately for academic achievement (e.g., August \& Shanahan, 2008). At the same time, bilingual children may learn different concepts and words in their L1 then in their L2, which is not taken into account when their vocabulary proficiency is only assessed in one language. Thus, there is a great need for more knowledge about typical bilingual children's vocabulary and the best ways of investigating the semantic knowledge that bilingual children possess across their L1 (the home language) and L2 (the societal language) (Cummins, 2000; Kohnert, 2013; Paradis, 2016; Peña, Bedore, \& Kester, 2016). Most studies today have focused on Spanish-English bilinguals, and less is known about vocabulary development among bilinguals in a European

\footnotetext{
${ }^{1}$ Statped-Center for Special Needs Education, Norway, Department of Special Needs Education, University of Oslo, Metropolitan University, Faculty of Education and International Studies, Oslo, Norway

2 Department of Education, University of Oslo, Norway

${ }^{3}$ Applied Psychology and Human Development, University of Toronto, Canada

${ }^{4}$ Statped-Center for Special Needs, Norway

${ }^{5}$ Department of Special Needs Education
} 
context. The main purpose of the present cross-sectional study is to investigate the vocabulary knowledge of several language groups of emergent bilingual children and the utility of a conceptual scoring approach that combines the vocabulary items known in the L1 or the L2. The L1 languages represented in the present study_Albanian, Somali, Tamil, Turkish, Urdu/Panjabi, and Vietnamese — are among the largest immigrant languages in Norway.

\section{L1 Vocabulary Proficiency Among Bilingual Children of Immigrants}

Vocabulary acquisition in bilingual children's two languages is highly sensitive to language exposure (Hurtado, Marchman, \& Fernald, 2008). The number of dialogue partners who speak the two languages (Gathercole, 2016; Haman et al., 2017; Rydland, Aukrust, \& Fulland, 2013) and the amount and quality of exposure in the L1 and L2 (Gámez \& Levine, 2013; Grosjean, 2016; Place \& Hoff, 2016) result in considerable variability in the contexts of home language (L1) and societal language (L2) vocabulary acquisition.

Maintaining L1 in a minority situation is challenging, and research conducted in the US context has demonstrated that bilingual children of immigrants might show a relatively rapid attrition of L1 skills, even in school contexts where bilingual education programs are offered (e.g.Cobo-Lewis, Pearson, Eilers, \& Umbel, 2002; Dixon, Zhao, Quiroz, \& Shin, 2012). In minority language contexts, children may demonstrate stronger receptive than expressive vocabulary skills in the $\mathrm{L} 1$, which may be related to more restricted and less active use of the L1 (e.g. de Abreu, Cruz-Santos, Tourinho, Martin, \& Bialystok, 2012; Hammer et al., 2014). Even though expressive vocabulary lags behind receptive vocabulary among both monolingual and bilingual children (Gibson, Oller, Jarmulowicz, \& Ethington, 2011), the receptive-expressive gap tends to be more pronounced in bilingual children's L1 than in their L2 (Gibson et al., 2011; Laufer \& Paribakht, 1998).

However, there is variability in the commitment to maintain the L1 among immigrant groups in the same host country (Extra \& Yagmur, 2010; Haman et al., 2017; Pham \& 
Kohnert, 2014; Scheele, Leseman, \& Mayo, 2010). For example, speaking Norwegian at home is very common among immigrants from Vietnam and Pakistan. These groups have lived in Norway for a long time. But almost two-thirds of Albanian-speaking people mostly speak Albanian at home (Statistics Norway, 2016). A similar emphasis on maintaining L1 use in the home has also been found in Turkish immigrant families in Norway (Rydland et al., 2013). A study of Turkish-Norwegian bilingual children suggested that the children were more proficient in their L1 Turkish than their L2 Norwegian (Grover, Lawrence, \& Rydland, 2016). But the opposite trend was documented in a study of Urdu-Norwegian-speaking bilingual children who appeared to be more proficient in their L2, Norwegian, than in their L1, Urdu (Lervåg \& Aukrust, 2010). As in other immigrant-receiving countries, maintaining and improving heritage language proficiency in the Norwegian context may be linked to an array of factors, length of residence in the new country, parental education, characteristics of ethnic networks established by immigrant groups and language policies in the host country (Cummins \& Persad, 2014; Gathercole, 2016). Likewise, a multitude of factors may contribute to variance in the L1 maintenance and L2 language competencies of the relatively recent Somali immigrant population and of the more established Tamil immigrant population in Norway (Fuglerud \& Engebrigtsen, 2006). For example, some immigrant groups in Norway have well-established volunteer networks in the big cities, which offer children L1 education and exposure to the culture of origin (e.g., Tamil-speaking immigrants from Sri Lanka). Besides exposure at home, children from other immigrant communities in Norway (e.g., Albanian, Somalian, Turkish, Urdu, and Vietnamese-speaking communities) are exposed to their L1 language and culture primarily in their respective houses of worship (Statistics Norway, 2016).

One can find a handful of studies that examine the development of L1 and L2 children's vocabularies (e.g.Mancilla-Martinez \& Lesaux, 2011). Whether the focus is on the 
development in L1 and L2 vocabulary, the relationships between L1-L2 vocabulary and its contributions to reading comprehension in typical learners, or assessment issues concerning L1 and L2 vocabulary development in clinical populations, these studies tend to examine specific L1-L2 combinations one at a time. There is scant detailed item-based information about the development of specific vocabulary in the L1 and L2 of children growing up in immigrant families; nor is there much comparative information about differences in L1 maintenance and L2 development across different L1 language groups exposed to the same societal language. In this cross-sectional study, we extend the existing research by investigating simultaneously, across successive age groups, the specific L1 and L2 vocabulary skills of children of immigrants coming from six different L1 backgrounds, all acquiring Norwegian, the societal language.

\section{L2 Vocabulary Proficiency Among Bilingual Children of Immigrants}

The vocabulary gap between bilingual and monolingual children in the language of schooling (L2) has been established across numerous studies (August \& Shanahan, 2008; Farnia \& Geva, 2011; Hammer et al., 2014; Lervåg \& Aukrust, 2010; Melby-Lervåg \& Lervåg, 2014; Snow \& Kim, 2007). In spite of reports that bilingual children may acquire vocabulary items at a faster pace than their monolingual peers, there is also evidence to suggest that this increase may not be enough to close the vocabulary gap. Mancilla-Martinez and Lesaux (2011) followed Spanish-English bilingual children ages 4-12 and found that the bilingual children from low-income households started out below and remained behind monolingual children in their L2 English. Similar results were reported in a Canadian study tracking grades 1-6 second-language learners (Farnia \& Geva, 2011) and a Greek study involving grades 2-4 second-language learners tracking their L2 Greek vocabulary (Simos, Sideridis, Mouzaki, Chatzidaki, \& Tzevelekou, 2014). 
The L2 vocabulary gap is evident in both receptive (Bialystok, Luk, Peets, \& Yang, 2010; Smithson, Paradis, \& Nicoladis, 2014) and expressive vocabulary (Karlsen, Lyster, \& Lervag, 2016). However, due to the many demographic and cultural differences between immigrant populations and the general population as well as between different immigrant groups, there are methodological challenges involved in teasing apart the confounding of bilingualism, SES, policies, and cultural traditions when the vocabulary of children of immigrants is the subject of investigation (Shany, Geva, \& Melech-Feder, 2010). Research conducted in the Norwegian context suggests that the school performance of Norwegian children coming from Vietnamese and Tamil immigrant families is stronger than that of immigrant children from other countries of origin and that higher performance in these groups cannot be attributed to differences in parental education only but rather, to a stronger educational drive (Bakken \& Hyggen, 2018).

Due to the lack of large-scale longitudinal studies and cross-sectional studies that track bilingual children's L2 vocabulary acquisition over time or across age groups, little is known about whether the vocabulary gap between monolingual and bilingual children is reduced over time or whether there are language group differences in performance. In the present cross-sequential study, we compare the receptive and expressive vocabulary of bilingual children in different age groups (6-13) to a Norwegian norming sample.

\section{Conceptual Vocabulary in Bilingual Children}

Bilingual children may be familiar with the meaning of a word in one language but not in the other. Thus, their vocabulary (semantic knowledge) is distributed across two languages (Cobo-Lewis et al., 2002). Researchers have called for a monitoring of vocabulary development in both languages to improve the understanding of bilingual children's vocabulary trajectories (e.g. Bedore, Peña, Garcia, \& Cortez, 2005; Core, Hoff, Rumiche, \& Señor, 2013; Kohnert, Kan, \& Conboy, 2010). The need to develop sensitive assessment tools 
and procedures to evaluate L1 and L2 semantic knowledge has been raised by several researchers (Kohnert, 2013; Sheng, Bedore, Peña, \& Fiestas, 2013).

A few studies involving young children have taken this more fine-tuned approach to capturing the semantic knowledge of L1 and L2 vocabularies (Core et al., 2013; Gross, Buac, \& Kaushanskaya, 2014; Mancilla-Martinez \& Vagh, 2013; Pearson, Fernandez, \& Oller, 1993). Such approaches consider familiarity with the L1 and/or the L2 vocabulary and propose the generation of a conceptual (semantic) vocabulary score that reflects the total number of words known in the L1 and the L2. To illustrate, in a longitudinal study involving 36 young bilingual children from low-income homes in the US, Mancilla-Martinez and Vagh (2013) assessed the children's vocabulary skills in Spanish (L1) and English (L2) between the ages of 24 and 36 months. Consistent with previous research, these young bilinguals performed significantly below the national monolingual norms in both Spanish and English vocabularies. In line with previous research, the growth in English vocabulary outpaced that of Spanish vocabulary, irrespective of home-language use and exposure. However, the conceptual score calculated on the basis of the overall number of words that the children knew in English and/or Spanish narrowed the vocabulary gap between bilingual and monolingual children.

Gross et al. (2014) compared both the receptive and expressive vocabularies of five- to seven-year-old Spanish- and English-speaking simultaneous bilingual and sequential bilingual children and monolingual English-speaking children. The results demonstrated that simultaneous bilinguals outperformed sequential bilinguals (who acquired the L2 after the age of three) on both L1 and L2 vocabulary measures. Monolingual children outperformed these two bilingual groups in both receptive and expressive vocabulary knowledge in English. By calculating conceptual scores, the significant difference in receptive vocabulary between simultaneous bilingual and monolingual children disappeared. However, on the receptive 
measure, sequential bilingual children still scored significantly below simultaneous bilingual and monolingual children. Still, using conceptual scoring showed that monolingual children outperformed both bilingual groups in expressive vocabulary but that the differences between simultaneous and sequential bilingual children were no longer significant.

To sum up, several studies have shown that single-language assessments may underestimate bilingual children's overall semantic knowledge and that procedures additively considering semantic knowledge in the $\mathrm{L} 1$ and/or the $\mathrm{L} 2$ provide a more accurate estimate. It is also important to notice that different conclusions may be reached depending on whether receptive or expressive vocabulary measures are used, as receptive and expressive vocabularies do not provide identical estimates of semantic knowledge (Schmitt, 2014). Thus, in the present study, we intend to capture emergent bilingual children's semantic knowledge by assessing their receptive and expressive vocabularies in their L1 and L2 and calculating a conceptual score to capture the total number of vocabularies known in L1 and/or L2 according to groups.

\section{The Norwegian Context}

As is the case in other immigration-absorbing countries, immigrants tend to settle in large cities (OECD, 2010). Immigrant parents often have lower earnings and lower education rates than overall rates in the native-born Norwegian population (Statistics Norway, 2016). However, length of residence is positively related to educational level (Bakken \& Hyggen, 2018) The immigrant groups in this study_Albanian, Somali, Tamil, Turkish, Urdu/Panjabi, and Vietnamese - arrived as working immigrants in the 1970s (Urdu/Panjabi and Turkish), as refugees in the late 1970s and 80s (Vietnamese and Tamil), as refugees from the Balkan war between 1989 and 2004 (Albanian), and from the war in Somalia in 2000.

Of the Norwegian population, about $16 \%$ comprise either immigrants or children of immigrants. However, in schools in certain districts in the greater Oslo area, immigrant 
children comprise $50 \%-90 \%$ of the student population. The main language of instruction in schools is Norwegian, and L1 educational support is no longer facilitated by the schools on a regular basis (Loona \& Wennerholm, 2017). Approximately $71 \%$ of one- to five-year-old children of immigrants attend preschool prior to age five, in contrast with $91 \%$ among their monolingual peers.

\section{The Present Study}

The main purpose of the present cross-sectional study was to investigate the L1 and L2 receptive and expressive vocabulary skills of bilingual elementary school children and the extent to which their conceptual vocabulary scores differed from those of monolingual children. We also investigated whether there were language group differences in the bilingual children's vocabulary performance. We examined bilingual children's L1, L2, and conceptual vocabulary skills in the age group 6-13, guided by the following research questions:

1. What are the bilingual children's L1 receptive and expressive vocabulary skills in the different age groups?

2. How do the bilingual children's L2 receptive and expressive vocabulary skills compare with those of the monolingual norming samples?

3. How do the bilingual children's conceptual receptive and expressive vocabulary skills compare with those of the monolingual norming samples?

\section{Method}

\section{Participants}

The sample consisted of 542 (250 boys and 292 girls) bilingual children aged 6-13 (grades 1-7). Table 1 shows the distribution of the children by gender and age groups. insert Table 1 here 
Children whose home language was either Albanian, Somali, Tamil, Turkish, Urdu/Punjabi, or Vietnamese were recruited from 36 public elementary schools in the greater Oslo area. Participants with Tamil as their L1 were recruited from three Tamil after-school cultural and linguistic resource centers. The participants attended schools located in multiethnic neighborhoods where parental income, work, and literacy levels were generally below the national average (Statistics Norway, 2016). The sample excluded children with identified learning disabilities (for example, developmental language disorders or dyslexia). An independent t-test showed no significant gender effect on L1 $(t=-1.32, p=0.431)$ and L2 $(\mathrm{t}=0.31, \mathrm{p}=0.753)$ receptive vocabularies. However, girls significantly outperformed boys on L1 expressive vocabulary $(\mathrm{t}=-1.77, \mathrm{p}=0.000)$. No gender difference was evident in L2 expressive vocabulary $(\mathrm{t}=0.314, \mathrm{p}=0.753)$.

Questionnaires to assess demographic information were distributed via the schools to the parents (in Norwegian and in the children's respective L1s). Sixty percent $(\mathrm{N}=327)$ of the parents returned these questionnaires. The majority of the children from whom we obtained background information were born in Norway $(84 \%, \mathrm{~N}=274)$ and had attended Norwegian preschool for an average of two years. Unfortunately, few parents $(\mathrm{N}=73)$ provided information about their own educational levels. ${ }^{6}$

\section{Measures $^{7}$}

Vocabulary was assessed with receptive and expressive vocabulary measures administered in both the L1 and the L2.

\footnotetext{
${ }^{6}$ Because of the low response rate, we were unable to use demographic information in the analyses of the full sample.

${ }^{7}$ Permission for translation for research purposes in this project was provided by GL Assessment for the British Picture Vocabulary Scale (BPVS-II) and by the authors E. Ottem and J. Frost for Expressive Vocabulary.
} 
L1 and L2 receptive vocabulary. The British Picture Vocabulary Scale (BPVS-II) (Dunn, Dunn, Whetton, \& Burley, 1997) was translated and adapted to Norwegian conditions (Lyster, Horn, \& Rygvold, 2010), was adapted to the respective languages included in this study, and was then used to assess receptive vocabulary. The BPVS-II Norwegian version includes 144 items (12 blocks) of increasing difficulty. For each item, the children had to point to one of four line drawings corresponding to a word spoken by the test leader. As noted by several researchers, it is important to modify test procedures when assessing bilingual children (e.g. Peña, 2007; Peña et al., 2016). When we administered the L1 and L2 versions of the BPVS-II, all children started with item 1 in both languages. We used the stop criterion of the BPVS-II Norwegian vocabulary manual, so the testing was terminated when eight or more out of the 12 items in a block were answered incorrectly. Each correct item was given one point. We calculated the percentage of the numbers of children who passed each block. There was a steady decrease in the percentage of children who were able to move on to a subsequent 12-item block in each of the six languages we assessed. This trend was observed both in the L1 and L2 assessments and suggests that there was a small chance for the examinee to pass the next block if he/she failed the former one.

L1 and L2 expressive vocabulary. The Norwegian Språk 6-16 test (Language 6-16 test) (Ottem \& Frost, 2005) was adapted to the home languages under study and was used to assess expressive vocabulary skills. The expressive vocabulary measure comprised two subtests consisting of 14 antonym items and 12 word definition items. In the antonym items, the children responded to each orally presented single word with an antonym (e.g., "What is the opposite of pretty?" or "What is the opposite of optimist?"). In the word definition items, the children were asked to describe or define a word orally (e.g., "What is a reward?"). The assessment was terminated after three consecutive incorrect responses for both antonyms and 
word definitions. Each correct response was assigned one point, and the raw score consisted of the total number of correct items for the antonym and the word definition subtest.

We also calculated the percentage of participants who responded correctly to each item of the antonym and the definition subtests. The definition subtest showed a steady decrease in the percentage of correctly identified items. Two items in the antonym subtest, on the other hand, were more difficult than the item to follow. However, because of the discontinue rule that students had to be wrong on three consecutive items before testing stopped, these item-level challenges did not cause a situation in which students had to stop the test and were not presented with easier items.

Performance on the Norwegian vocabulary tasks was compared to that of the Norwegian norming samples of receptive vocabulary $(\mathrm{N}=495)$ and expressive vocabulary ( $\mathrm{N}$ =900). (See Appendix 1 for demographic information about the language groups, age groups, and monolingual norming samples.) There were no known children with learning disabilities or suspected special educational needs in the two norming samples (Lyster et al., 2010; Ottem \& Frost, 2003).

Translation procedures. In accordance with the Standards of Educational and Psychological Testing, two professional translators created independent versions of the receptive and the expressive vocabulary assessments for each of the six home-language versions (Association American Educational Research, American Psychological Association, \& National Council on Measurement in Education, 1999). The main goal of this endeavor was to create translated versions that were as equivalent as possible to the Norwegian versions in terms of the concepts used and the word-level difficulty (related to abstractness, relevance etc.). It was not feasible to compare the children's L1 skills with the national standards for language attainment in the country of origin. As some languages may not have a distinct word for a certain concept and other languages may have many different nuanced words when 
referring to one concept, it is obviously challenging to translate word-level items perfectly. Word frequency lists were not available across all home-language groups and might not have been appropriate for young children who grew up in a minority language context. Thus, when considering a word's frequency level, we carefully discussed with the translators whether the word was appropriate for the children in their specific bicultural and bilingual context. Based on these considerations, we chose the best available options. The translators had high levels of L1 and L2 competence and relevant professional/academic backgrounds as linguists, interpreters, teachers, or researchers. The two translators for each language included one representative of the domain of education/pedagogy and one with a linguistic/research background. The two translators and a Norwegian project group consisting of professionals and research experts in the field of language development discussed the translations of each receptive and expressive vocabulary item. Once the draft list of translated words was complete, six independent translators, who were not involved in the previous phase, backtranslated the home-language versions to Norwegian to determine whether the original version of the test was retained. When this was not the case, the items were discussed by the team until a consensus was reached.

\section{Procedures}

All the children were assessed individually in their L1 and L2 at their respective schools. The assessors had professional backgrounds as speech and language therapists, school psychologists, or trained graduate students. The L1 was assessed by assessors from the relevant home-language backgrounds, and the L2 was evaluated by native Norwegian assessors. As noted in the manual for the BPVS-II, it is considered poor practice for standardized assessments to be repeated within six months (Dunn et al., 1997). Thus, to minimize the test-retest transfer effect (Sattler, 2008), there was a six- to eight-month gap between the assessments in the L1 and the L2. The order of assessments in the L1 and the L2 
was counterbalanced; half the bilingual children in each age group were assessed in their L1 first and were tested in Norwegian (their L2) about 6-8 months later. The other half of the bilingual sample was assessed in Norwegian first and later in their L1.

Some attrition occurred between the first and second data collection waves. This attrition was attributed to (a) absence from school (missing completely at random) or (b) the fact that we, at the onset of the project, had an unexpected delay of test material in L1 (receptive vocabulary, L1: $\mathrm{N}=14$ and L2: $\mathrm{N}=0$; expressive vocabulary, L1: $\mathrm{N}=67$ and L2: $\mathrm{N}=36)$.

\section{Analyses}

To address the questions of the bilingual children's L1 vocabulary skills in the different age groups, we conducted a two-way MANOVA, with the age groups and the six home-language groups as the two independent variables and with their L1 receptive and expressive vocabularies as the dependent variables.

To address how bilingual children's L2 vocabularies compared with those of the two monolingual norming comparison samples, we conducted a two-way ANOVA for receptive vocabulary and a two-way ANOVA for expressive vocabulary. The independent variables were age groups and bilingual versus monolingual. The rationale for running two ANOVAs was that the monolingual norming data was not the same for receptive and expressive vocabulary.

The same procedures were applied when comparing the bilingual students' conceptual scores to the monolingual scores.

Cohen's D was calculated to compare the effect size differences between the bilingual children's L2 receptive and expressive mean scores and receptive and expressive conceptual vocabulary mean scores and the monolingual norming samples' means (see Tables 3 and 4). 
The conceptual score considered the total number of words whose meanings were familiar to the children in their L1 and/or L2 (See Table 2). insert Table 2 here

The conceptual scores consisted of the sum of the unique vocabulary items known in the L1 or the L2 (singlets) combined with the vocabulary known in both the L1 and the L2 (doublets). The children did not earn double credit for knowing a word in both languages. Because of the time gap between the L1 and L2 assessments, we used the bilingual children's age levels at the last test point when conducting age-related comparisons between the bilingual children's conceptual scores and the vocabulary scores of the majority norming sample. Thus, it is important to note that part of the scores feeding into the conceptual scores of the bilingual children were obtained in their L1 or L2 when they were 6-8 months younger than the monolingual norming sample. This might give the bilingual children a disadvantage in the comparison.

\section{Results}

Tables 3 and 4 present summary statistics for the receptive and expressive vocabularies and the receptive and expressive conceptual scores, respectively, of each age group as well as the monolingual norming sample's vocabulary by age group. No interaction effects were found in any of the analyses.

As shown in Tables 3 and 4, there was a steady increase in vocabulary with the increase in age of the samples.

\section{- Insert Tables 3 and 4 here}

\section{The Bilingual Children's L1 Receptive and Expressive Vocabularies}

There was a significant age effect on the children's L1 receptive vocabulary $(\mathrm{F}=27.943, \mathrm{p}=0.000)$, except for the comparison between the two oldest age groups $(11.0-$ 11.11 and 12.0-12.11), as well as a significant effect of age on L1 expressive vocabulary 
$(\mathrm{F}=22.724, \mathrm{p}=0.000)$. There was also a significant home-language effect of $\mathrm{L} 1$ receptive vocabulary $(F=9.341, p=0.000)$. A follow-up Bonferroni comparison showed that the L1 receptive vocabularies of the Tamil-Norwegian-speaking and the Turkish-Norwegianspeaking children were significantly higher than the L1 receptive vocabulary of the other home-language groups. There was also a significant home-language group effect on L1 expressive vocabulary skills $(\mathrm{F}=6.818, \mathrm{p}=0.000)$. The L1 expressive vocabulary means of the Albanian-speaking, Tamil-speaking, and Turkish-speaking children were significantly higher than those of the other home-language groups.

\section{The Bilingual Children's L2 Receptive and Expressive Vocabularies}

As Tables 3 and 4 show, there was a significant age-related increase in the bilingual children's L2 receptive vocabulary $(F=53.516, \mathrm{p}=0.000)$ as well as a significant overall age-related increase in the children's L2 expressive vocabulary skills $(\mathrm{F}=56.463, \mathrm{p}=0.000)$, except for the two youngest age groups (ages 6.0-6.11 and 7.0-7.11).

There were also significant differences in the L2 receptive vocabulary scores of the home-language groups $(\mathrm{F}=11.523, \mathrm{p}=0.000)$. A Bonferroni post-hoc comparison showed that the means of the L2 receptive vocabulary scores of the Tamil-speaking group were significantly higher than those of the other language groups. Additionally, the means of the L2 receptive vocabulary scores of the children who spoke Albanian and Vietnamese were significantly higher than those of the children who spoke Turkish, Somali, and Urdu. There was also a significant home-language group effect on L2 expressive vocabulary skills $(\mathrm{F}=9.076, \mathrm{p}=0.000)$. A follow-up Bonferroni post-hoc comparison test of expressive vocabulary showed that the Tamil-speaking group achieved significantly higher Norwegian expressive vocabulary scores than the other language groups.

A two-way ANOVA showed that the mean receptive vocabulary of the monolingual norming sample was significantly higher than the bilingual children's L2 receptive vocabulary 
$(\mathrm{F}=535.126, \mathrm{p}=0.000)$. A comparison across age groups in terms of the differences between the bilingual children's and the monolingual norming sample's receptive vocabulary scores showed large negative effect sizes in favor of the monolingual children, especially in the youngest age group $(d=-1.78$; see Table 3$)$ with these effect sizes still pronounced with increased age (see Table 3).

When comparing L2 expressive vocabulary scores with those of the monolingual norming sample (Table 4), we found that the monolingual norming sample achieved significantly stronger expressive vocabulary than the bilingual children $(\mathrm{F}=34.645$, $\mathrm{p}=0.000$ ). The effect size across age groups also indicated smaller differences in the older age groups (Cohen's D decreased from 1.68 to 1.02; see Table 4).

\section{The Bilingual Students' Conceptual Receptive and Expressive Vocabularies}

When analyzing the bilingual students' conceptual scores with those of the monolingual norming sample, we found that the mean receptive conceptual score of the bilingual students did not differ from the mean score of the monolingual norming sample $(\mathrm{F}=2.390, \mathrm{p}=0.122)$. The three youngest age groups' $(6.0-6-11,7.0-7.11,8.0-8.11)$ conceptual receptive scores were somewhat lower than the scores of the corresponding age groups in the monolingual norming sample, resulting in small negative effect sizes $(d=-0.17$, $\mathrm{d}=-0.31$, and $\mathrm{d}=-0.08$ ). However, from age nine and up, the bilingual children's receptive conceptual scores were higher than the scores of the monolingual norming sample. To illustrate, the effect size difference in the youngest age group was not significant $(d=0.17)$, while the effect difference in the oldest age group was strong and significant in favor of the bilingual group $(\mathrm{d}=0.52)$. The bilingual students' receptive $\mathrm{L} 1, \mathrm{~L} 2$, and conceptual scores are compared to those of the monolingual norming sample in Figure 1. The figure illustrates that the conceptual scores surpass those of the monolingual norming sample in the older age groups. 
- Figure 1

Figure 1. The bilingual children's L1, L2, and conceptual receptive vocabulary scores compared with those of the monolingual norming sample by age group

Similar comparisons were made for the conceptual expressive vocabulary scores. The conceptual expressive vocabulary score (i.e., the conceptual score for the bilinguals and expressive score for the monolinguals) was the dependent variable. The results yielded a significant effect of age and a significant bilingual versus monolingual effect $(\mathrm{F}=67.452$, $p=0.000)$. As shown in Table 4, the effect sizes of the comparisons between the bilingual and the monolingual children in terms of their conceptual expressive scores were strong in the four youngest age groups (with effect sizes ranging from $d=-0.51$ to $d=-0.78$ ) and moderate in the two oldest age groups (with effect sizes of $d=-0.45$ and $d=-0.39$ ). Still, the gap between the bilingual groups and the monolingual group was larger for the expressive than for the receptive conceptual scores, as illustrated in Figure 2.

- Figure 2

Figure 2. The bilingual children's L1, L2, and conceptual expressive vocabulary scores compared with that of the monolingual norming sample by age group

\section{Discussion}

Several interesting findings emerge from this cross-sectional study regarding the vocabulary knowledge of bilingual children in Norway who come from different homelanguage backgrounds across a large age range.

\section{Improvement in the $\mathrm{L} 1$ with Increased Age}

The results indicate a gradual increase in the $\mathrm{L} 1$ receptive and expressive vocabularies across the elementary school years. This finding is interesting, given the fact that L1 and literacy support are not offered on a regular basis in Norwegian schools and that maintaining 
the L1 in a minority context is challenging. The social support and opportunities to use the L1 that are provided by immigrant organizations, such as houses of worship, Saturday schools, cultural and educational community centers, and so on aided in L1 maintenance among many of the student participants in this study (see also Rydland et al., 2013; Scheele et al., 2010). In the current study, the children with home-language backgrounds from Albania, Sri Lanka, and Turkey appear to have a stronger command of their L1 than their counterparts from the other home-language groups. Several possible explanations for these differences can be offered. First, the procedure of recruiting children who speak Tamil from the Tamil resource centers might have contributed to a sample for whom support for L1 academic skills is emphasized to a large extent. The center offers L1 teaching in reading, writing, and other content areas in addition to cultural activities. The Turkish- and Albanian-speaking children of immigrants in Norway also tend to maintain use of the first language at home and have strong support networks outside school through cultural activities in mosques and community centers (Statistics Norway, 2016). The Turkish-speaking children's L1 skills also receive a boost from regular visits to their extended families in Turkey (Pettersen \& Østby, 2013). However, it is important to note that there is large variability within children's L1 vocabulary skills, attributable, to some extent, to varying degrees of exposure and maintenance of the L1 (e.g. Hoff, 2014). As we were unable to compare the children's L1 skills with those of the appropriate norming samples in the countries of origin, we could not determine the level of L1 maintenance vis-à-vis that of peers growing up in the country of origin.

\section{Vocabulary Scores did not Catch up with the Norwegian Norms}

The present study shows a large and significant gap between the bilingual children's command of Norwegian vocabulary and that of the monolingual norming samples. This gap is maintained in all age groups. Similar findings have been documented across studies that compare bilingual children of immigrants with the national norms (Geva \& Farnia, 2012; 
Melby-Lervåg \& Lervåg, 2014). This gap is not surprising, given that it takes a long time to develop native-like proficiency. The increase in command of vocabulary with increasing age in the societal language—Norwegian—varies across home-language groups. Results show that the Tamil-speaking and Vietnamese-speaking children tend to outperform the other bilingual groups (Bakken \& Hyggen, 2018). Compared with the Tamil-speaking children, the Vietnamese-speaking children do not appear to maintain their L1 skills to the same extent. In this sense, the two groups seem to develop slightly different bilingual profiles in the process of acquiring their L2. Together, these findings reflect the different patterns of L1 and L2 vocabulary skills across the different home-language groups in Norway (Statistics Norway, 2016).

\section{Conceptual Scoring Reduced the Gap to Norwegian Norms}

An additive approach that gives credit to word meanings known in the L1 and/or the L2 considerably increases the estimates of bilingual children's overall semantic knowledge. An important finding of the present study is that when children's L1 and L2 vocabulary knowledge is considered jointly, many bilingual children's performance is close to that of the monolingual norming sample. Thus, the vocabulary gap between the two cohorts, which is highly evident when the bilingual children are only evaluated in Norwegian as their L2, diminishes considerably, and in fact disappears altogether in some groups, when more of the children's distributed vocabulary repertoire is considered. Importantly, this trend is evident in the children's receptive and expressive vocabulary skills and across the different homelanguage and age groups. Most of the previous research on conceptual scoring has focused primarily on the L1 and L2 semantic knowledge of young children exposed to typologically related languages, such as Spanish and English. The present study used this approach in a larger sample of school-aged bilingual children who speak typologically different languages. 
To our best knowledge, the current study is the first to extend the conceptual scoring approach across six different home-language groups and a broader age range.

\section{Implications for Assessment, Educational Practices, and Future Research}

An increased understanding of the complexity and different aspects of bilingual children's vocabulary knowledge might contribute to a deeper comprehension of the complexity of assessing lexical skills of bilingual children. Bilingual children may struggle with the language of instruction in school, especially when it is provided in the societal language only. More nuanced knowledge about the semantic skills of bilingual learners may lead to the development of more sophisticated assessment procedures and aid in the process of determining whether persistent difficulties in developing adequate vocabulary in the L2 are due to language impairment or simply to inadequate exposure (e.g. Mancilla-Martinez \& Vagh, 2013; Paradis, Genesee, \& Crago, 2011; Peña et al., 2016).

The gap between bilingual and monolingual children is worrisome, especially in the early school years, as the development of the L2 is necessary for academic success. In line with Gibson and colleagues' (2011) work, this study shows that such a gap is even more problematic in expressive than in receptive vocabulary. Clearly, there is a need for more intensive and systematic vocabulary intervention programs that support L2 vocabulary and align with the distributed language skills of bilingual children across the school years.

In this cross-sectional study, we detected a consistent progress in command of lexical entries with increased age, assessed both receptively (in comprehension tasks) and expressively (in communication). However, L2 learners whose schooling occurs primarily in the majority language do not entirely catch up with their monolingual peers, even after many years. At the same time, an additive approach that jointly considers lexical entries in both L1 and L2 provides a more nuanced picture, distinguishing between individual differences in the extent of bilingual children's overall semantic repertoires. It is reasonable to expect that the 
profiles of children who come from immigrant backgrounds and who are familiar with the meanings of many words in their L1 but with fewer word meanings in their L2 are not identical to the profiles of children whose familiarity with the meanings of words is restricted in both their L1 and L2. Generally, educational systems tend to ignore this distributed vocabulary knowledge (Cummins, 2000). Additional research is obviously needed to explore the relationships between these different profiles, the rate of vocabulary growth, and academic achievement. The strong results noted for the bilingual Tamil-speaking children underscore the complexity of the issue. These children demonstrate that it is possible to excel in both L1 and L2, that "one size does not fit all," and that contextual factors should be considered. The current study also suggests that more research is needed concerning appropriate assessment procedures that can be reliably applied in bilingual contexts where language impairment is suspected. Measuring the children's vocabulary in their L1 and L2 via the same concepts provides an advantage in trying to estimate the lexical repertoire of bilingual children.

Our results show that when using conceptual scoring, bilingual children catch up to monolingual children, even surpassing the latter in receptive vocabulary. The bilingual children did not fully catch up with the monolingual children in expressive vocabulary, but the gap was much smaller than when comparing the L2 conceptual expressive vocabulary to the vocabulary of the monolingual norming sample.

There are limitations in the way we can interpret our results, given the lack of background information. There might also be differences between linguistic structures and cultural contexts that can explain differences in vocabulary development that we have not uncovered. For example, specific words may vary in their difficulty across L1 and L2. However, the test level difficulty seemed to increase reasonably in both L1 and L2 in each of the six languages, giving us support for having given all children a fair opportunity to show their vocabulary knowledge even when there was a stop criterion. Also, even when the test 
level difficulty increased, the vocabulary gap between the minority and majority groups disappeared or grew smaller when using conceptual scoring, supporting the main implication of the study that conceptual scoring is a more fair and valid procedure to evaluate vocabulary skills in bilingual children. The conceptual scoring is based on two assessments. Children may answer an item correctly by chance in the BPVS-II (because they have to point to one of four line drawings), which may contribute to increasing the children's conceptual scores in receptive vocabulary. It is difficult to fully diminish this problem when investigating conceptual scoring in receptive vocabulary. Assessments that allow bilingual children to hear vocabulary items in both languages during the administration of the assessment may solve this problem but introduce new ones.

Allowing children two assessments (L1 and L2) instead of one becomes less challenging when measuring expressive vocabulary, because the children cannot guess their answers in expressive items. Interestingly, the results of the conceptual scoring in expressive vocabulary confirm that the gap between the bilingual children and the monolingual norming sample tends to decrease.

Further research should include conceptual scoring in longitudinal designs. Also, we were unable to fully shed light on the differences related to home-language groups. To do so in a systematic manner, we would need more information on parental education, immigration history, and work. Nonetheless, by investigating the distributed vocabulary repertoire of immigrants' bilingual children who grow up in Norway, the present study's findings underscore the limitations of solely relying on monolingual approaches to assess bilingual students' vocabulary knowledge. The findings also show that conceptual scoring provides a more optimistic and nuanced picture of emergent bilingual children's vocabulary. 


\section{References}

Association American Educational Research, American Psychological Association, \& National Council on Measurement in Education. (1999). Standards for educational and psychological testing. Washington: American Educational Research Association.

August, D. \& Shanahan, T. (2008). Developing reading and writing in second-language learners: Lessons from the report of the National Literacy Panel on Language-Minority Children and Youth. New York: Routledge.

Bakken, A. \& Hyggen, C. (2018). Trivsel og utdanningsdriv blant minoritetselever i videregående : Hvordan forstå karakterforskjeller mellom elever med ulik innvandrerbakgrunn? (NOVA rapport 1/2018).

Bedore, L. M., Peña, E. D., Garcia, M., \& Cortez, C. (2005). Conceptual Versus Monolingual Scoring: When Does It Make a Difference? Language, Speech, and Hearing Services in Schools, 36(3), 188-200. doi:10.1044/0161-1461(2005/020)

Bialystok, E., Luk, G., Peets, K. F., \& Yang, S. (2010). Receptive vocabulary differences in monolingual and bilingual children. Bilingualism: Language and Cognition, 13(04), 525-531. doi:10.1017/S1366728909990423

Cobo-Lewis, A. B., Pearson, B. Z., Eilers, R. E., \& Umbel, V. C. (2002). Effects of bilingualism and bilingual education on oral and written English skills: a multifactor study of standardized test outcomes. In D. K. Oller \& R. E. Eilers (Ed.), Language and Literacy in Bilingual Children (p. 64-97). Clevedon: Multilingual Matters.

Core, C., Hoff, E., Rumiche, R., \& Señor, M. (2013). Total and conceptual vocabulary in Spanish English bilinguals from 22 to 30 months: Implications for assessment. Journal of Speech, Language, and Hearing Research, 56(5), 1637-1649. doi:10.1044/1092-4388(2013/11-0044)

Cummins, J. (2000). Language, power, and pedagogy: Bilingual children in the crossfire. Clevedon: Multilingual Matters.

Cummins, J., \& Persad, R. (2014). Teaching through a multilingual lens: the evolution of EAL policy and practice in Canada. Education Matters: The Journal of Teaching and Learning, 2(1), 3-40.

de Abreu, P. M. E., Cruz-Santos, A., Tourinho, C. J., Martin, R. \& Bialystok, E. (2012). Bilingualism enriches the poor enhanced cognitive control in low-income minority children. Psychological Science, 23(11), 1364 1371. doi:10.1177/0956797612443836

Dixon, L. Q., Zhao, J., Quiroz, B. G., \& Shin, J.-Y. (2012). Home and community factors influencing bilingual children's ethnic language vocabulary development. International Journal of Bilingualism, 16(4), 541-565. doi:10.1177/1367006911429527

Dunn, L. M., Dunn, L. M., Whetton, C., \& Burley, J. (1997). The British Picture Vocabulary Scale (2 ${ }^{\text {nd }}$ ed.). London: NFER Nelson.

Extra, G., \& Yagmur, K. (2010). Language proficiency and socio-cultural orientation of Turkish and Moroccan youngsters in the Netherlands. Language and Education, 24(2), 117-132. doi:10.1080/09500780903096561

Farnia, F., \& Geva, E. (2011). Cognitive correlates of vocabulary growth in English language learners. Applied Psycholinguistics, 32(4), 711-738. doi:10.1017/S0142716411000038

Fuglerud, O., \& Engebrigtsen, A. (2006). Culture, networks and social capital: Tamil and Somali immigrants in Norway. Ethnic and Racial Studies, 29(6), 1118-1134. doi:10.1080/01419870600960388

Gámez, P. B., \& Levine, S. C. (2013). Oral language skills of Spanish-speaking English language learners: The impact of high-quality native language exposure. Applied Psycholinguistics, 34(4), 673-696. doi.org/10.1017/S0142716411000919

Gathercole, V. C. M. (2016). Factors Moderating Proficiency in Bilingual Speakers. In E. Nicoladis \& S. Montanari (Ed.), Bilingualism across the lifespan: Factors moderating language proficiency (123-140). Berlin: de Gruyter Mouton.

Geva, E., \& Farnia, F. (2012). Developmental changes in the nature of language proficiency and reading fluency paint a more complex view of reading comprehension in ELL and EL1. Reading and Writing, 25(8), 1819-1845. doi:10.1007/s11145-011-9333-8

Gibson, T. A., Oller, D. K., Jarmulowicz, L., \& Ethington, C. A. (2011). The receptive-expressive gap in the vocabulary of young second-language learners: Robustness and possible mechanisms. Bilingualism: Language and Cognition, 15(1), 102-116. doi:10.1017/S1366728910000490 
Grosjean, F. (2016). The Complementarity Principle and its impact on processing, acquisition, and dominance. In C. Silva-Corvalán \& J. Treffers-Daller (Eds.), Language Dominance in Bilinguals: Issues of Measurement and Operationalization, (66-84). Cambridge, UK: Cambridge University Press

Gross, M., Buac, M., \& Kaushanskaya, M. (2014). Conceptual scoring of receptive and expressive vocabulary measures in simultaneous and sequential bilingual children. American Journal of Speech-Language Pathology, 23(4), 574-586. doi:10.1044/2014_AJSLP-13-0026

Grover, V., Lawrence, J., \& Rydland, V. (2016). Bilingual preschool children's second-language vocabulary development: The role of first-language vocabulary skills and second-languagetalk input. International Journal of Bilingualism, 22(2). doi:10.1177/1367006916666389

Haman, E., Wodniecka, Z., Marecka, M., Szewczyk, J., Białecka-Pikul, M., Otwinowska, A., Mieszkowska, K., Luniewska, M., Kolak, J., Miękisz, A., Kacprzak, A., Banasik, N. \& Malgorzata, F. (2017). How does L1 and L2 exposure impact L1 performance in bilingual children? Evidence from Polish-English migrants to the United Kingdom. Frontiers in Psychology, 8, 1444.doi: /10.1017/S0142716411000919

Hammer, C. S., Hoff, E., Uchikoshi, Y., Gillanders, C., Castro, D. C., \& Sandilos, L. E. (2014). The language and literacy development of young dual language learners: A critical review. Early Childhood Research Quarterly, 29(4), 715-733. doi:10.1016/j.ecresq.2014.05.008

Hoff, E. (2014). Language development (5th ed.). Australia: Wadsworth Cengage learning.

Hurtado, N., Marchman, V. A., \& Fernald, A. (2008). Does input influence uptake? Links between maternal talk, processing speed and vocabulary size in Spanish-learning children. Developmental science, 11(6), F31-F39. doi:10.1111/j.1467-7687.2008.00768.x

Karlsen, J., Lyster, S. H., \& Lervåg, A. (2016). Vocabulary development in Norwegian L1 and L2 learners in the kindergarten-school transition. Journal of Child Language, 1-25. doi:10.1017/S0305000916000106

Kohnert, K. (2013). Language disorders in bilingual children and adults. San Diego: Plural Publ.

Kohnert, K., Kan, P. F., \& Conboy, B. T. (2010). Lexical and grammatical associations in sequential bilingual preschoolers. Journal of Speech, Language, and Hearing Research, 53(3), 684-698. doi:10.1044/1092-4388(2009/08-0126)

Laufer, B., \& Paribakht, T. S. (1998). The relationship between passive and active vocabularies: Effects of language learning context. Language Learning, 48(3), 365-391. doi:10.1111/0023-8333.00046

Lervåg, A., \& Aukrust, V. G. (2010). Vocabulary knowledge is a critical determinant of the difference in reading comprehension growth between first and second language learners. Journal of Child Psychology and Psychiatry, 51(5), 612-620. doi:10.1111/j.1469-7610.2009.02185.x

Loona, S., \& Wennerholm, M. (2017). Heritage Language Education in Norway and Sweden. In O. E. Kagan, M. M. Carreira \& C. H. Chik (Ed.), The Routledge Handbook of Heritage Language Education: From Innovation to Program Building (313-326). New York: Routledge.

Lyster, S.-A. H., Horn, E., \& Rygvold, A.-L. (2010). Ordforråd og ordforrådsutvikling hos norske barn og unge. Spesialpedagogikk, 9, 35-43.

Mancilla-Martinez, J., \& Lesaux, N. K. (2011). Early home language use and later vocabulary development. Journal of Educational Psychology, 103(3), 535. doi:10.1037/a0023655

Mancilla-Martinez, J., \& Vagh, S. B. (2013). Growth in toddlers' Spanish, English, and conceptual vocabulary knowledge. Early Childhood Research Quarterly, 28(3), 555-567. doi:10.1016/j.ecresq.2013.03.004

Melby-Lervåg, M., \& Lervåg, A. (2014). Reading comprehension and its underlying components in second-language learners: A meta-analysis of studies comparing first- and second-language learners. Psychological Bulletin Psychological Bulletin, 140(2), 409-433. doi:10.1037/a0033890

OECD. (2010). Closing the Gap for Immigrant Students: Policies, Practice and Performance. Paris: OECD.

Ottem, E., \& Frost, J. (2005). Språk 6-16: Screening test: Manual. Oslo: Bredtvet kompetansesenter.

Paradis, J. (2016). The Development of English as a Second Language With and Without Specific Language Impairment: Clinical Implications. Journal of Speech, Language, and Hearing Research, 59(1), 171-182. doi:10.1044/2015_JSLHR-L-15-0008

Paradis, J., Genesee, F., \& Crago, M. B. (2011). Dual language development and disorders: a handbook of bilingualism and second language learning (2 ed.). Baltimore, Md.: Brookes.

Pearson, B. Z., Fernandez, S. C., \& Oller, D. K. (1993). Lexical development in bilingual infants and toddlers: Comparison to monolingual norms. Language Learning, 43(1), 93-120. doi:10.1111/j.1467-1770.1993.tb00174.x

Peña, E. D. (2007). Lost in Translation: Methodological Considerations in Cross-Cultural Research. Child development, 78(4), 1255-1264. Doi: https://10.1111/j.1467-8624.2007.01064.x 
Peña, E. D., Bedore, L. M., \& Kester, E. S. (2016). Assessment of language impairment in bilingual children using semantic tasks: Two languages classify better than one. International Journal of Language \& Communication Disorders, 51(2), 192-202. doi.org/10.1017/S0142716411000919

Pettersen, S. V., \& Østby, L. (2013). Skandinavisk komparativ statistikk om integrering: Innvandrere i Norge, Sverige og Danmark. Samfunnsspeilet, 5, 7.

Pham, G., \& Kohnert, K. (2014). A longitudinal study of lexical development in children learning Vietnamese and English. Child Development, 85(2), 767-782. doi:10.1111/cdev.12137

Place, S., \& Hoff, E. (2016). Effects and noneffects of input in bilingual environments on dual language skills in 2 $1 / 2$-year-olds. Bilingualism: Language and Cognition, 19(5), 1023-1041.

Rydland, V., Aukrust, V. G., \& Fulland, H. (2013). Living in neighborhoods with high or low co-ethnic concentration: Turkish-Norwegian-speaking students' vocabulary skills and reading comprehension. International Journal of Bilingual Education and Bilingualism, 16(6), 657-674. doi:10.1080/13670050.2012.709224

Sattler, J. M. (2008). Assessment of children: cognitive foundations (5th ed. ed.). San Diego, Calif: Jerome M. Sattler Publ.

Scheele, A. F., Leseman, P. P., \& Mayo, A. Y. (2010). The home language environment of monolingual and bilingual children and their language proficiency. Applied Psycholinguistics, 31(1), 117-140. doi:10.1017/S0142716409990191

Schmitt, N. (2014). Size and depth of vocabulary knowledge: What the research shows. Language Learning, 64(4), 913-951. doi:10.1111/lang.12077

Shany, M., Geva, E. \& Melech-Feder, L. (2010). Emergent literacy in children of immigrants coming from a primarily oral literacy culture. Written Language \& Literacy, 13(1), 24-60. doi.org/10.1017/S0142716411000919

Sheng, L., Bedore, L. M., Peña, E. D. \& Fiestas, C. (2013). Semantic development in Spanish-English bilingual children: Effects of age and language experience. Child Development, 84(3), 1034-1045. doi:10.1111/cdev.12015

Simos, P. G., Sideridis, G. D., Mouzaki, A., Chatzidaki, A. \& Tzevelekou, M. (2014). Vocabulary growth in second language among immigrant school-aged children in Greece. Applied Psycholinguistics, 35(03), 621-647. doi:10.1017/S0142716412000525

Smithson, L., Paradis, J. \& Nicoladis, E. (2014). Bilingualism and receptive vocabulary achievement: Could sociocultural context make a difference? Bilingualism: Language and Cognition, 17(04), 810-821. doi:10.1017/S1366728913000813

Snow, C. E., \& Kim Y.-S. (2007). Large problem spaces: The challenge of vocabulary for English language learners. In R. K. Wagner, A. E. Muse, \& K. R. Tannenbaum (Eds.), Vocabulary acquisition: Implications for reading comprehension (123-139). New York, NY, US: Guilford Press.

Statistics Norway. (2016). Immigrants and Norwegian-born to immigrant parents, 1 January 2016. Retrieved from https://www.ssb.no/en/befolkning/statistikker/innvbef/aar/2016-03-03Association 
Table 1: The distribution of participants by gender and age

$\begin{array}{cccccccc}\text { Age } & \mathbf{6 . 0}- & \mathbf{7 . 0}- & \mathbf{8 . 0}- & \mathbf{9 . 0}- & \mathbf{1 0 . 0}- & \mathbf{1 1 . 0}- & \mathbf{1 2 . 0}- \\ \text { Groups } & \mathbf{6 . 1 1} & \mathbf{7 . 1 1} & \mathbf{8 . 1 1} & \mathbf{9 . 1 1} & \mathbf{1 0 . 1 1} & \mathbf{1 1 . 1 1} & \mathbf{1 2 . 1 1} \\ \begin{array}{c}\text { Boys } \\ (\mathbf{N = 2 5 0})\end{array} & 17 & 46 & 39 & 50 & 44 & 32 & 22 \\ \begin{array}{c}\text { Girls } \\ (\mathbf{N = 2 9 2})\end{array} & 27 & 44 & 47 & 40 & 63 & 45 & 26 \\ \begin{array}{c}\text { Total } \\ (\mathbf{N}=\mathbf{5 4 2})\end{array} & 44 & 90 & 86 & 90 & 107 & 77 & 48\end{array}$

Table 2: Illustration of conceptual scoring

L1 L2 Conceptual

$\begin{array}{llll}\text { Student 1 } & 1 & 0 & 1 \\ \text { Student 2 } & 0 & 1 & 1 \\ \text { Student 3 } & 1 & 1 & 1\end{array}$


Table 3: Receptive vocabulary; L1, L2, conceptual, and monolingual mean scores: descriptive statistics, MANOVA and ANOVA results, and effect sizes (Cohen's D), bilingual vs. monolinguals and conceptual vs. monolingual by age group

\begin{tabular}{|c|c|c|c|c|c|c|c|c|c|c|}
\hline & Age 6.0-6.11 & Age 7.0-7.11 & Age 8.0-8.11 & Age 9.0-9.11 & $\begin{array}{c}\text { Age 10.0- } \\
10.11\end{array}$ & $\begin{array}{c}\text { Age 11.0- } \\
11.11\end{array}$ & $\begin{array}{c}\text { Age 12.0- } \\
12.11\end{array}$ & $\mathbf{N}$ & Age Effect & $\begin{array}{c}\text { Home } \\
\text { Language } \\
\text { Effect }\end{array}$ \\
\hline \multirow{3}{*}{$\begin{array}{l}\text { L1 } \\
\alpha 0.96-0.99\end{array}$} & 57.28 & 62.79 & 76.24 & 83.05 & 94.52 & 107.89 & 106.18 & 528 & $\mathrm{~F}=27.934$ & $\mathrm{~F}=9.341$ \\
\hline & $(\mathrm{SD}=28.47)$ & $(\mathrm{SD}=30.22)$ & $(\mathrm{SD}=30.75)$ & $(\mathrm{SD}=29.99)$ & $(\mathrm{SD}=26.78)$ & $(\mathrm{SD}=18.65)$ & $(\mathrm{SD}=21.18)$ & & $\mathrm{p}=.000$ & $\mathrm{p}=.000$ \\
\hline & $\mathrm{N}=25$ & $\mathrm{~N}=73$ & $\mathrm{~N}=93$ & $\mathrm{~N}=97$ & $\mathrm{~N}=97$ & $\mathrm{~N}=83$ & $\mathrm{~N}=60$ & & & \\
\hline \multirow{3}{*}{$\begin{array}{l}\text { Norwegian (L2) } \\
\text { a } 0.06-0.99\end{array}$} & 49.98 & 59.97 & 69.79 & 74.90 & 85.37 & 95.48 & 99.63 & 542 & $\mathrm{~F}=53.516$ & $\mathrm{~F}=11.523$ \\
\hline & $(\mathrm{SD}=17.84)$ & $(\mathrm{SD}=18.43)$ & $(\mathrm{SD}=16.91)$ & $(\mathrm{SD}=18.15)$ & $(\mathrm{SD}=17.81)$ & $(\mathrm{SD}=16.80)$ & $(\mathrm{SD}=16.17)$ & & $\mathrm{p}=.000$ & $\mathrm{p}=.000$ \\
\hline & $\mathrm{N}=44$ & $\mathrm{~N}=90$ & $\mathrm{~N}=86$ & $\mathrm{~N}=90$ & $\mathrm{~N}=107$ & $\mathrm{~N}=77$ & $\mathrm{~N}=48$ & & & \\
\hline \multirow{3}{*}{$\begin{array}{l}\text { Norwegian } \\
\text { Norm }\end{array}$} & 77.91 & 86.00 & 94.21 & 96.98 & 106.93 & 114.53 & 116.10 & 495 & $\mathrm{~F}=100.168$ & \\
\hline & $(\mathrm{SD}=13.19)$ & $(\mathrm{SD}=14.63)$ & $(\mathrm{SD}=10.99)$ & $(\mathrm{SD}=12.40)$ & $(\mathrm{SD}=11.95)$ & $(\mathrm{SD}=9.83)$ & $(\mathrm{SD}=11.70)$ & & $\mathrm{p}=.000$ & \\
\hline & $\mathrm{N}=75$ & $\mathrm{~N}=61$ & $\mathrm{~N}=99$ & $\mathrm{~N}=63$ & $\mathrm{~N}=54$ & $\mathrm{~N}=80$ & $\mathrm{~N}=63$ & & & \\
\hline Cohen's D: & -1.78 & -1.56 & -1.71 & -1.42 & -1.42 & -1.38 & -1.17 & & & \\
\hline \multirow{2}{*}{\multicolumn{11}{|c|}{$\begin{array}{l}\text { Bilinguals vs. } \\
\text { Monolinguals }\end{array}$}} \\
\hline & & & & & & & & & & \\
\hline \multirow{3}{*}{$\begin{array}{l}\text { Conceptual } \\
\text { Score }\end{array}$} & 76.00 & 80.06 & 92.61 & 102.03 & 111.34 & 121.27 & 123.23 & 524 & $\mathrm{~F}=45.951$ & $\mathrm{~F}=11.716$ \\
\hline & $(\mathrm{SD}=23.53)$ & $(\mathrm{SD}=22.52)$ & $(\mathrm{SD}=24.37)$ & $(\mathrm{SD}=21.74)$ & $(\mathrm{SD}=18.28)$ & $(\mathrm{SD}=14.57)$ & $(\mathrm{SD}=15.14)$ & & $\mathrm{P}=.000$ & $\mathrm{P}=.000$ \\
\hline & $\mathrm{N}=8$ & $\mathrm{~N}=77$ & $\mathrm{~N}=89$ & $\mathrm{~N}=92$ & $\mathrm{~N}=98$ & $\mathrm{~N}=94$ & $\mathrm{~N}=66$ & & & \\
\hline Cohen's D: & -0.10 & -.0 .31 & -.0 .08 & +0.17 & +0.28 & +0.54 & +.0 .52 & & & \\
\hline \multicolumn{11}{|l|}{ Conceptual } \\
\hline \multicolumn{11}{|l|}{ scores vs } \\
\hline Monolingual ${ }^{8}$ & & & & & & & & & & \\
\hline
\end{tabular}

\footnotetext{
${ }^{8}$ Conceptual score versus Monolingual score
} 
Table 4: Expressive vocabulary; L1, L2, conceptual, and monolingual mean scores: Descriptive statistics, MANOVA and ANOVA results, and effect size (Cohen's D), bilinguals vs. monolinguals and bilingual conceptual vs. monolinguals by age group

\begin{tabular}{|c|c|c|c|c|c|c|c|c|c|c|}
\hline & Age 6.0-6.11 & Age 7.0-7.11 & Age 8.0-8.11 & Age 9.0-9.11 & $\begin{array}{c}\text { Age 10.0- } \\
10.11\end{array}$ & $\begin{array}{l}\text { Age 11.0- } \\
11.11\end{array}$ & $\begin{array}{c}\text { Age 12.0- } \\
12.11\end{array}$ & $\mathbf{N}$ & Age Effect & $\begin{array}{c}\text { Home } \\
\text { Language } \\
\text { Effect }\end{array}$ \\
\hline \multirow{3}{*}{$\begin{array}{l}\text { L1 } \\
\alpha 0.85-0.90\end{array}$} & 5.92 & 6.59 & 8.00 & 9.43 & 10.98 & 12.74 & 14.98 & 467 & $\mathrm{~F}=22.724$ & $\mathrm{~F}=6.818$ \\
\hline & $(\mathrm{SD}=3.68)$ & $(\mathrm{SD}=3.78)$ & $(\mathrm{SD}=3.99)$ & $(\mathrm{SD}=5.37)$ & $(\mathrm{SD}=4.82)$ & $(\mathrm{SD}=4.75)$ & $(\mathrm{SD}=5.09)$ & & $\mathrm{p}=.000$ & $\mathrm{p}=.000$ \\
\hline & $\mathrm{N}=12$ & $\mathrm{~N}=63$ & $\mathrm{~N}=82$ & $\mathrm{~N}=89$ & $\mathrm{~N}=84$ & $\mathrm{~N}=80$ & $\mathrm{~N}=57$ & & & \\
\hline \multirow{3}{*}{$\begin{array}{l}\text { Norwegian } \\
\text { (L2) } \\
\alpha \text { 0.85-0.90 }\end{array}$} & 4.14 & 5.67 & 7.46 & 8.51 & 10.80 & 12.81 & 13.67 & 506 & $\mathrm{~F}=56.463$ & $\mathrm{~F}=9.076$ \\
\hline & (SD 1.65) & $(\mathrm{SD}=2.33)$ & $(\mathrm{SD}=3.74)$ & $(\mathrm{SD}=3.68)$ & $(\mathrm{SD}=3.53)$ & $(\mathrm{SD}=4.34)$ & $(\mathrm{SD}=3.90)$ & & $\mathrm{p}=.000$ & $\mathrm{p}=.000$ \\
\hline & $\mathrm{N}=37$ & $\mathrm{~N}=80$ & $\mathrm{~N}=80$ & $\mathrm{~N}=85$ & $\mathrm{~N}=103$ & $\mathrm{~N}=75$ & $\mathrm{~N}=46$ & & & \\
\hline \multirow[t]{3}{*}{ Norwegian norm } & 7.78 & 8.91 & 12.25 & 14.75 & 16.45 & 17.09 & 18.75 & 900 & $\mathrm{~F}=180.817$ & \\
\hline & $(\mathrm{SD}=2.58)$ & $(\mathrm{SD}=2.91)$ & $(\mathrm{SD}=3.70)$ & $(\mathrm{SD}=4.04)$ & $(\mathrm{SD}=3.90)$ & $(\mathrm{SD}=4.08)$ & $(\mathrm{SD}=3.31)$ & & $\mathrm{p}=.000$ & \\
\hline & $\mathrm{N}=153$ & $\mathrm{~N}=107$ & $\mathrm{~N}=172$ & $\mathrm{~N}=102$ & $\mathrm{~N}=121$ & $\mathrm{~N}=134$ & $\mathrm{~N}=111$ & & & \\
\hline $\begin{array}{l}\text { Cohen's D: } \\
\text { bilinguals vs. } \\
\text { monolinguals }\end{array}$ & -1.68 & -1.23 & -1.29 & -1.61 & -1.52 & -1.02 & -1.40 & & & \\
\hline \multirow{3}{*}{$\begin{array}{l}\text { Conceptual } \\
\text { score }\end{array}$} & 6.00 & 7.39 & 9.32 & 11.42 & 13.54 & 15.23 & 17.33 & 520 & $\mathrm{~F}=42.713$ & $\mathrm{~F}=10.093$ \\
\hline & $(\mathrm{SD}=2.6)$ & $(\mathrm{SD}=3.1)$ & $(\mathrm{SD}=3.8)$ & $(\mathrm{SD}=4.6)$ & $(\mathrm{SD}=4.8)$ & $(\mathrm{SD}=4.2)$ & $(\mathrm{SD}=4.0)$ & & $\mathrm{p}=.000$ & $\mathrm{p}=.000$ \\
\hline & $\mathrm{N}=8$ & $\mathrm{~N}=77$ & $\mathrm{~N}=88$ & $\mathrm{~N}=92$ & $\mathrm{~N}=98$ & $\mathrm{~N}=94$ & $\mathrm{~N}=63$ & & & \\
\hline $\begin{array}{l}\text { Cohen's D: } \\
\text { Conceptual score } \\
\text { vs. Monolingual9 }\end{array}$ & -0.69 & -0.51 & -0.78 & -0.76 & -0.67 & -0.45 & -0.39 & & & \\
\hline
\end{tabular}

\footnotetext{
${ }^{9}$ Conceptual score vs Monolingual score
} 
Appendix 1: Number of Participants, language, and age group

AGE

LANGUAGE
6.0-6.11

7.0-

7.11 $8.0-\quad 9.0-\quad 10.0-$

$8.11 \quad 9.11$
11.0- 12.0- TOTAL

$11.11 \quad 12.11$

$\begin{array}{lcccccccc}\text { Albanian } & 3 & 11 & 12 & 10 & 11 & 12 & 5 & 64 \\ \text { Somali } & 6 & 8 & 6 & 15 & 17 & 8 & 8 & 68 \\ \text { Tamil } & 3 & 8 & 17 & 13 & 21 & 10 & 9 & 81 \\ \text { Turkish }^{\mathbf{1 0}} & 10 & 30 & 17 & 22 & 22 & 11 & 9 & 121 \\ \text { Urdu }^{\mathbf{1 1}} & 14 & 18 & 24 & 16 & 22 & 23 & 12 & 129 \\ \text { Vietnamese } & 8 & 15 & 10 & 14 & 14 & 13 & 5 & 79 \\ \text { TOTAL bilingual } & 44 & 90 & 86 & 90 & 107 & 77 & 48 & 542 \\ \text { TOTAL monolingual } & 75 & 61 & 99 & 63 & 54 & 80 & 63 & 495\end{array}$

Receptive

TOTAL monolingual

153

107

172

102

121

134

111

900

Expressive

\footnotetext{
${ }^{10}$ The larger sample size of the Turkish-speaking sample reflects the fact that this sample is one of the largest immigrant groups in Norway (SSB 2010; SSB 2016).

${ }^{11}$ The larger sample size of Urdu-speaking sample reflects the fact the Pakistani-speaking sample is the largest immigrant group in Norway (SSB 2010; SSB 2016).
} 
THE ADVANTAGES OF JOINTLY CONSIDERING FIRST AND SECOND LANGUAGE 